\title{
Fine Tuning of Real Time PCR as a First Tool for the Detection of G143A Substitution in Venturia inaequalis Samples
}

\author{
Ceren Turan ${ }^{1}$, Irene Maja Nanni ${ }^{1}$, Lucia Landi ${ }^{2}$, Alessandro Pirondi ${ }^{1}$, Marina Collina ${ }^{1 *}$ \\ ${ }^{1}$ Department of Agricultural and Food Sciences, University of Bologna, Bologna, Italy \\ ${ }^{2}$ Department of Agricultural, Food and Environmental Sciences, Polytechnic University of Marche, Ancona, Italy \\ Email: *marina.collina@unibo.it
}

How to cite this paper: Turan C.,, Nanni, I. M., Landi, L., Pirondi, A., \& Collina, M. (2021) Fine Tuning of Real Time PCR as a First Tool for the Detection of G143A Substitution in Venturia inaequalis Samples. American Journal of Plant Sciences, 12, 960-974.

https://doi.org/10.4236/ajps.2021.126065

Received: April 20, 2021

Accepted: June 27, 2021

Published: June 30, 2021

Copyright $\odot 2021$ by author(s) and Scientific Research Publishing Inc. This work is licensed under the Creative Commons Attribution International License (CC BY 4.0).

http://creativecommons.org/licenses/by/4.0/

\begin{abstract}
Apple scab caused by Venturia inaequalis (Cke.) Wint. is the most important disease of apple trees worldwide and requires a high number of fungicide applications. The G143A substitution in the inhibitor binding site of cytochrome $b$ of $V$. inaequalis confers a high level of resistance to strobilurins targeting the $b c_{1}$ complex. The aim of this work was to substitute the labor intensive in vitro assays, with the faster quantitative PCR. An allele-specific qPCR method with a newly designed primer set was successfully developed to quantitatively determine the frequency of QoI-resistant A143 allele in populations of $V$. inaequalis. To be able to suggest that the molecular method could be applied as unique and robust technique, we carried out in vitro sensitivity test to trifloxystrobin; first testing the relative germination and subsequently confirmed with the quantification of mutated allele frequencies by qPCR on forty-nine Italian $V$. inaequalis populations. qPCR gave a similar pattern to that obtained using in vitro conidial germination test in predominantly sensitive and resistant populations, the variability between these two tests was observed in some heterogeneous populations. The qPCR assay developed in this study efficiently quantifies the A143 allele and we can conclude that this method could be useful for the study of the fungicide resistance at population level in the fields, giving a quick response also with a large amount of samples.
\end{abstract}

\section{Keywords}

Venturia inaequalis, qPCR, Strobilurin, Cytochrome $b$

\section{Introduction}

Apple scab, caused by Venturia inaequalis (Cooke) Winter, is the main disease 
in almost all apple growing areas in the world, and in Italy requires numerous fungicide applications (from 10 to 20 and more) especially in Northern areas because of frequent rain and fairly high temperatures in the early growth stages.

Old protectant fungicides (dithiocarbamates, dithianon, captan and dodine) have an important role in apple scab control. In the early 1970s, the most important fungicides for scab control were the benzimidazoles, but in a few years they were dramatically affected by resistance development. This led to a return to the use of dodine until the late 1970s, when fenarimol's registration started the Sterol Biosynthesis Inhibiting (SBI) fungicide period. These fungicides have been used for many years with triazoles but they were progressively affected by resistance from the middle of the 1980s to nowadays [1].

An improvement of control was made possible by anilinopyrimidines introduced in the middle of the 1990s and by strobilurins in the late 1990s. Strobilurin fungicides, belonging to the group of Quinone outside Inhibitors (QoIs), are highly effective against a wide range of fungal pathogens. The mode of action of QoIs consists in inhibiting mitochondrial respiration by binding at the so-called Qo site of cytochrome $b$. Cytochrome $b$ is part of the cytochrome $b c 1$ complex (or complex III), located in the inner mitochondrial membrane of fungi and other eukaryotes [2] [3]. Strobilurins, first as kresoxim-methyl and later as trifloxystrobin, permitted improvements in apple scab control because they made it possible to extend spray intervals between treatments even up to ten days [4].

The first occurrences of resistance to QoIs, also with a reduction in performance, were reported for several pathogens, including $V$. inaequalis [5] [6] [7]. The first mechanism of resistance observed in many phytopathogenic fungi was a single-nucleotide mutation in the cytochrome $b(c y t b)$ gene, leading to amino acid exchange [8]. Three of the most common amino acid substitutions were detected in several phytopathogenic fungi and Oomycetes that are resistant to QoIs: from glycine to alanine at position 143 (G143A), from phenylalanine to leucine at position 129 (F129L) and from glycine to arginine at position 137 (G137R) [9].

Sierotzki an collaborators detected for the first time the G143A substitution in cytochrome $b$ gene in QoI-resistant field isolates of plant pathogens [10]. This target site mutation has been identified in more than twenty species, including phytopathogenic Ascomycetes such as $V$. inaequalis [11], several powdery mildews [10] [12] and Alternaria species [6] [13] [14] [15]. This mutation was able to cause severe decreases of sensitivity (Resistance factor [RF] often higher than 100) and field control failure, while the other detected mutation, F129L, determined moderate effects on sensitivity and field performances. The $V$. inaequalis situation was more complex because the high reduction of $V$. inaequalis population sensitivity was not always related to the detected mutations or the field control reductions [16] [17] [18]. In these situation, the alternative respiration pathway was assumed to have an important function, however its in planta activity has not been clarified [19]. Consequently, the results on $V$. inaequalis were 
conflicting, showing different levels of inhibition from very low to high [20]. Another resistance mechanism; an external esterase able to metabolise the fungicide conferring a partial loss of control of kresoxim-methyl was reported [21]. However, studies proved that it was much less effective in the case of other strobilurins [18].

In Italian apple areas, a reduced activity of QoIs on apple scab has been suspected since 2000 and 2001 [22]. The field control complaints made by farmers in the last few years in Italy led to reconsider the application of these fungicides. Strobilurins were abandoned in some areas, especially where control failures were rather frequent, or utilized only in low risk periods, while in other areas they continue to be applied with the usual anti resistance recommendations. Some authors reported the presence of resistant populations of $V$. inaequalis [23] [24] and they defined in vitro values for resistant populations similar to the one defined in our previous work [22]. Moreover, Fontaine and collabrators [24] were in agreement with our previous study supporting the concept that the G143A substitution was almost always present in resistant populations and sometimes also in sensitive ones [25]. Even when it is present at very low frequencies, the mutation can be identified utilizing quantitative Real-Time PCR [26]. Once the resistance mechanism is known, it is often faster to use molecular techniques compared to biological assays. The in vitro methods are widely used for sensitivity screening among fungal populations. However, they are labor-intensive and time-consuming; moreover, only a part of the samples from orchards (generally no more than $50 \%-60 \%$ ) have conidia with a sufficient viability to be multiplied in order to carry out the in vitro assays. The main advantage of qPCR methods is their high sensitivity and cultivation-independency, in fact, qPCR allows the detection of small amounts of the desired allele in bulk samples, thus it eliminates the need to maintain pure cultures of the pathogens.

The allele-specific qPCR assay was successfully applied for QoI-resistant allele detection in response to QoI applications. In particular, the qPCR method has been applied for quantification of G143A substitution that confers QoI resistance in Alternaria spp. [27] Mycosphaerella graminicola [28], Plasmopara viticola [29] [30] Erysiphe necator and Pyrenophora teres [31] [32].

Qualitative or semi-quantitative techniques such as PCR-RFLP [33] allele-specific PCR (AS-PCR) and cleaved amplified polymorphic sequence (CAPS) assay were also used for detecting $V$. inaequalis resistance [24] [34]. Quantification of QoI resistant alleles in $V$. inaequalis populations has been developed [35] [36] [37] [38]. Our previous studies [22] [25] highlighted the occurrence of QoIs resistance in Italian $V$. inaequalis populations sampled from 2002 to 2005 with the presence of G143A substitution. The aim of the present work was to definitely substitute the labor intensive biological assays with a molecular one. In order to suggest the qPCR method as unique, robust and consistent, a large monitoring sampling $V$. inaequalis populations from 2002 to 2010 was carried out. A qPCR protocol was designed to quantitatively determine the frequency of G143A mutation and related 
to in in vitro sensitivity test performed to identify the QoIs resistance.

\section{Materials and Methods}

\subsection{Origin and Maintenance of Venturia inaequalis Populations}

Forty-nine bulk $V$. inaequalis populations were sampled in Northern Italy orchards during 2002-2010. $V$. inaequalis populations were collected in apple trees with different scab management: wild-type trees (WT), which have never been treated with fungicides and located in uncultivated areas of Northern Italy; untreated trees (UNT), which have never been exposed to QoIs; commercial orchards where several groups of fungicides, often including strobilurins, have been applied with good disease control (GC) or poor disease control (PC) i.e. with practical resistance to QoI fungicides). Samples consisted of 40 - 50 scabbed leaves randomly collected in each orchard from May to July.

In order to obtain populations with high viability, a drop of sterile water was put on 30 - $40 \mathrm{scab}$ lesions from each sample and conidia were harvested by rinsing with sterile water. The conidial concentration was adjusted to $(1-3) \times$ $10^{5}$ spores $/ \mathrm{mL}$ and inoculated on potted apple seedlings. Inoculated seedlings were incubated for $15-20$ days at $21^{\circ} \mathrm{C}$ in a greenhouse. All scabbed seedling leaves were then conserved in silica gel at $4^{\circ} \mathrm{C}$ for fungicide sensitivity assays and molecular analysis. In addition, scabbed-infected leaf discs obtained by a sterile cork borer ( $9 \mathrm{~mm} \varnothing)$ from 15 - 20 leaves for each population were stored at $-20^{\circ} \mathrm{C}$ until DNA extraction.

\subsection{In Vitro Fungicide Sensitivity Assays}

Sensitivity of $V$. inaequalis to trifloxystrobin (Sigma-Aldrich, St Louis, MO, USA) was determined by spore germination assay. Trifloxystrobin was solubilized in acetone and added to water-agar (2\% agar grade A; Becton, Dickinson and Company) to achieve the following concentrations: $0.001,0.01,0.1,2 \mathrm{mg} / \mathrm{L}$. The antibiotic streptomycin sulfate (Sigma-Aldrich) was added to water agar at a final concentration of $200 \mathrm{mg} / \mathrm{L}$. In each in vitro test, pieces of scabbed leaves (0.012 - $0.020 \mathrm{~g}$ ) were randomly collected from each sample and introduced in micro tubes with $1 \mathrm{~mL}$ of sterile water. After shaking, the conidial concentration was adjusted to $(1-3) \times 10^{5}$ spores/mL. Two drops of $20 \mu \mathrm{L}$ of spore suspension were placed on agar plates for every fungicide concentration and incubated for $24 \mathrm{~h}$ at $20^{\circ} \mathrm{C}$. 150 conidia per replicate were visually assessed using a microscope, counting those that had germinated. Two in vitro tests were performed for each population. The resistance response for each population was expressed as mean percent relative germination "RG\%" (percentage of germination at $2 \mathrm{mg} / \mathrm{L} /$ percentage of germination in untreated $\times 100$ ), as previously described [39].

\subsection{DNA Extraction}

The fungal genomic DNA was extracted directly from lyophilised scabbed leaves which were ground in liquid nitrogen by a CTAB-based method and then puri- 
fied through a Sepharose 6B (Sigma-Aldrich). Amount, purity and integrity of DNA samples were assessed on the basis of an absorbance ratio of $1.80-1.90$ at 260/280nm and of $1.90-2.30$ at 260/230nm using NanoQuant (Tecan, Grödig, Austria).

\subsection{Cloning of Cytochrome $b$ Gene of Sensitive and Resistant Strains of Venturia inaequalis}

A 413 bp fragment of cytochrome $b$ gene was amplified. Resistant and sensitive references were obtained from sensitive and resistant monoconidial isolates of $V$. inaequalis. CleavedSequencing reactions were done by Sanger methods using gene-specific primers (BMR Service, Padova, Italy). A BLASTN search was carried out in the NCBI database in order to confirm the strains. After PCR, excess primers were removed using GenElute PCR Clean-up kit (Sigma-Aldrich) and the species-specific PCR product ligated directly into the pGEM-T easy vector (Promega, Madison, WI, USA). Plasmids were transformed into Escherichia coli JM109 cells (Promega) according to a standard protocol, plasmid DNA was extracted using Quick Plasmid Miniprep Kit (Invitrogen, Carlsbad, CA), according to a manufacturer's protocol.

\subsection{Primers Set-Up}

The G143A substitution in $V$. inaequalis population was detected using the qPCR method. A specific primers set was designed. The forward primers FwS5418 and FwR5418 were used respectively for sensitive (S) and resistant (R) alleles, while the reverse common primer, R5548U, was used (Table 1). With the aim of verifying the qPCR efficiency (E) and specificity of each primer pair, different percentages of reference sensitive and resistant plasmidial DNA were analyzed: $100 \%$ S, $1 \%$ S + 99\% R, 5\% S + 95\% R, 10\% S + 90\% R, 50\% S + 50\% R, $99 \% \mathrm{~S}+1 \% \mathrm{R}, 100 \% \mathrm{R}$ (Figure 1). Even when it is present at low frequencies, the mutation can be identified utilizing quantitative Real-Time PCR. The ratio (\%) of the two alleles present in samples was calculated using the $\Delta C_{q}$ method according to the equation [40] $10^{\wedge}$ ( $C q \mathrm{~S}$ allele $-C q \mathrm{R}$ allele)/-slope); $\mathrm{R}(\mathrm{R} / 1+$ R) $\times 100=\mathrm{R}$ allele; where $C q$ is the quantification cycle and reflects the cycle number at which the fluorescence generated within the reaction of each sample crosses the threshold and the slope was calculated according to the standard curves, which were specific for each allele. The data are expressed as percentages of mutated allele.

Table 1. Primer sequences selected for qPCR analysis.

\begin{tabular}{ccccc}
\hline & Name & $\left(5^{\prime} \rightarrow 3^{\prime}\right)$ & Sequence & Amplicon (bp) \\
\hline qPCR & S 5418 & Forward & GGTCAAATGAGCCTATGGGG & 130 \\
& R 5418 & Forward & GGTCAAATGAGCCTATGGGC & \\
& 5548U & Reverse & CTGTTGTTAGGCTCTTCAATG & \\
\hline
\end{tabular}




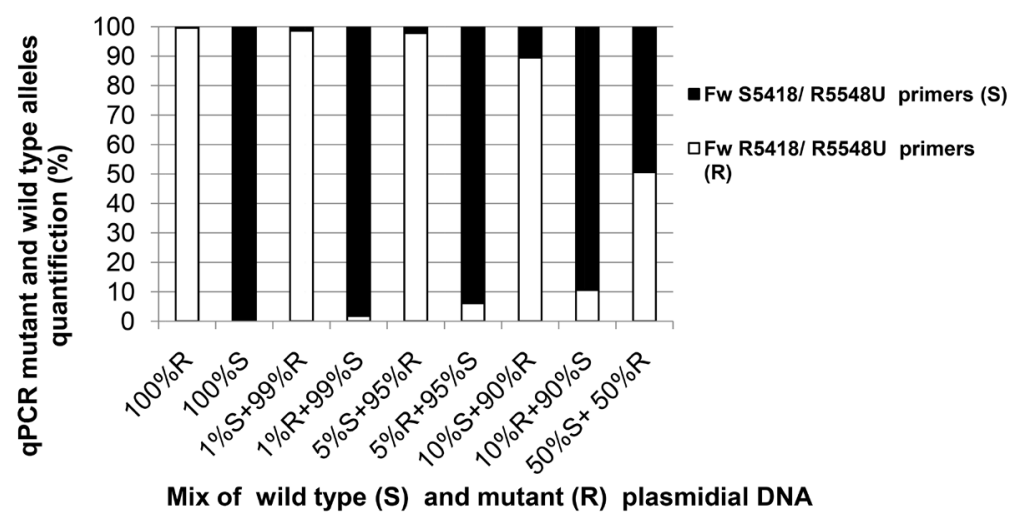

Figure 1. Specificity of Fw S5418/R5548U (for wild type allele) and Fw R5418/R5548U (for mutant allele) primers tested according to different mix concentrations of plasmidial DNA template obtained from monoconidial isolates of $V$. inaequalis. The ratio (\%) of the two alleles' presence in samples was calculated using the $\Delta \mathrm{C}_{\mathrm{q}}$ method (see Material and Methods section).

\subsection{Standard Curves Development}

Standard curves were obtained mixing $\mathrm{S}$ and $\mathrm{R}$ alleles strains (50\% $\mathrm{S}$ and $50 \% \mathrm{R}$ ) 10 -fold serial dilutions ranging from $20 \mathrm{ng} \times 10^{-3}$ to $20 \mathrm{ng} \times 10^{-6}$ of plasmid DNA. The standard curve efficiencies were: $\mathrm{S}$ allele, $\mathrm{E}=101.9 \%, \mathrm{R}$ allele, $\mathrm{E}=100.1 \%$. The high efficiency for each gene allowed the assumption that the genes are amplified with the same efficiency, and an average slope of -3.329 was used in the equation.

\subsection{Quantitative Real-Time PCR Conditions}

The qPCR analysis of the forty-nine $V$. inaequalis populations was performed using an ICycler-IQ5 (Bio-Rad). The reaction mixture was prepared in a final volume of $20 \mu \mathrm{L}$, including $10 \mu \mathrm{L}$ of $2 \times$ SYBR Green I (Bio-Rad), $1 \mu \mathrm{L}$ of forward and reverse primers (12.5 $\mu \mathrm{M}$ each), and $8 \mu \mathrm{L}$ of diluted DNA (1/5). Amplifications were performed in 96-well Hard-shell PCR plates (Bio-Rad). The following thermal cycling conditions were used: one cycle at $95^{\circ} \mathrm{C}$ for $3 \mathrm{~min}$ followed by 40 cycles at $95^{\circ} \mathrm{C}$ for $18 \mathrm{~s}, 55^{\circ} \mathrm{C}$ for $12 \mathrm{~s}$, and $72^{\circ} \mathrm{C}$ for $18 \mathrm{~s}$.

To verify the specificity of the product obtained, a melting curve was performed at the end of the PCR reaction with an increase of the temperature specificity of $0.05^{\circ} \mathrm{C} / \mathrm{s}$, from $55^{\circ} \mathrm{C}$ to $95^{\circ} \mathrm{C}$.

For each population, the specific primers for both QoI R and $\mathrm{S}$ alleles were analysed in each plate. The assays were carried out in duplicate, each experiment was repeated three times and the means comparisons was conducted. Data were calculated using the supplied Real-Time Detection System software version 3.0. for Windows.

\section{Results}

\subsection{Sensitivity Assays}

Eight WT and one UNT populations were found to be sensitive to trifloxystrobin with RG values from 0 to $9.2 \%$ (Table 2, Column B and Figure 2). Our 
Table 2. Results of biological and molecular assays.

\begin{tabular}{|c|c|c|c|c|c|}
\hline & & & In vitro assay & & Molecular analysis \\
\hline & & & A & B & $\mathrm{C}$ \\
\hline $\begin{array}{l}\text { Population } \\
\text { No }\end{array}$ & Year & $\begin{array}{c}\text { Management } \\
\text { characteristics }^{\mathrm{a}}\end{array}$ & $\begin{array}{c}\text { Sensitivity } \\
\text { classification }^{\mathrm{b}}\end{array}$ & $\begin{array}{c}\text { Relative } \\
\text { germination }^{c}(\%)\end{array}$ & $\begin{array}{c}\text { Mutated } \\
\text { alleles }^{\mathrm{d}}(\%)\end{array}$ \\
\hline 62 & 2003 & WT & $S$ & 0 & 0.07 \\
\hline 1202 & 2002 & WT & $S$ & 0 & 0.05 \\
\hline 426 & 2008 & WT & $S$ & 0 & 18.93 \\
\hline 202 & 2006 & GC & $S$ & 0 & 0.015 \\
\hline $12-3$ & 2003 & WT & $S$ & 0 & 0.02 \\
\hline 158 & 2005 & WT & $S$ & 0 & 21.32 \\
\hline 115 & 2004 & UNT & $S$ & 0 & 2.28 \\
\hline $228 \mathrm{I}$ & 2006 & WT & $S$ & 0.6 & 21.11 \\
\hline 226 & 2006 & WT & $S$ & 2.4 & 17.55 \\
\hline 96 & 2003 & GC & $S$ & 6.1 & 0.55 \\
\hline 136 & 2005 & WT & $S$ & 9.2 & 5.5 \\
\hline 156 & 2005 & GC & $S$ & 14.6 & 0.02 \\
\hline 427 & 2008 & GC & $S$ & 12.5 & 84.5 \\
\hline 319 & 2007 & $\mathrm{PC}$ & $\mathrm{R}$ & 42 & 31.01 \\
\hline 408 & 2008 & $\mathrm{PC}$ & $\mathrm{R}$ & 24.5 & 68.2 \\
\hline 229 & 2006 & $\mathrm{PC}$ & $\mathrm{R}$ & 29 & 91.68 \\
\hline 201 & 2006 & NOS & $\mathrm{R}$ & 14.6 & 0.015 \\
\hline 225 & 2006 & PC & $\mathrm{R}$ & 15.4 & 32.8 \\
\hline 144 & 2005 & $\mathrm{PC}$ & $\mathrm{R}$ & 35.03 & 99.27 \\
\hline 302 & 2007 & PC & $\mathrm{R}$ & 23.3 & 76.1 \\
\hline 533 & 2009 & PC & $\mathrm{R}$ & 39.76 & 23.01 \\
\hline 523 & 2009 & PC & $\mathrm{R}$ & 44.5 & 99.51 \\
\hline 161 & 2005 & $\mathrm{PC}$ & $\mathrm{R}$ & 31.4 & 5.97 \\
\hline 600 & 2010 & NOS & $\mathrm{R}$ & 34.33 & 56.77 \\
\hline 130 & 2005 & $\mathrm{PC}$ & $\mathrm{R}$ & 23.9 & 61.21 \\
\hline 602 & 2010 & PC & $\mathrm{R}$ & 50.3 & 56.79 \\
\hline 412 & 2008 & $\mathrm{PC}$ & $\mathrm{R}$ & 55.5 & 98.61 \\
\hline 88 & 2003 & PC & $\mathrm{R}$ & 46.5 & 99.09 \\
\hline 307 & 2007 & PC & $\mathrm{R}$ & 49.3 & 99.21 \\
\hline 411 & 2008 & $\mathrm{PC}$ & $\mathrm{R}$ & 53.8 & 99.49 \\
\hline 138 & 2005 & PC & $\mathrm{R}$ & 56 & 99.54 \\
\hline 507 & 2009 & PC & $\mathrm{R}$ & 56.5 & 99.15 \\
\hline 508 & 2009 & PC & $\mathrm{R}$ & 58.14 & 98.51 \\
\hline 504 & 2009 & PC & $\mathrm{R}$ & 66.45 & 99.4 \\
\hline
\end{tabular}




\section{Continued}

\begin{tabular}{cccccc}
\hline 535 & 2009 & PC & R & 66.71 & 72.73 \\
616 & 2010 & PC & R & 67.02 & 99.26 \\
605 & 2010 & PC & R & 68.17 & 93.35 \\
512 & 2009 & PC & R & 68.19 & 99.24 \\
BA3 & 2010 & NOS & R & 68.8 & 54.87 \\
612 & 2010 & - & R & 71.8 & 89.63 \\
611 & 2010 & PC & R & 72.87 & 98.29 \\
506 & 2009 & PC & R & 76.29 & 91.74 \\
503 & 2009 & PC & R & 76.43 & 99.54 \\
550 & 2009 & PC & R & 77.6 & 99.32 \\
551 & 2009 & PC & R & 79.45 & 95.2 \\
546 & 2009 & PC & R & 84.9 & 99.29 \\
543 & 2009 & PC & R & 87.97 & 99.21 \\
549 & 2009 & PC & R & 88 & 97.8 \\
87 & 2003 & PC & R & 97.3 & 99.07 \\
\hline
\end{tabular}

${ }^{a}$ WT: wild-type; UNT: untreated; NOS: no strobilurins used; GC: good control and use of strobilurins; PC: poor control and use of strobilurins; -: management characteristics not available. ' $S$ trobilurin sensitivity: $\mathrm{S}=$ sensitive $\mathrm{EC}_{50}<0.065 \mathrm{mg} / \mathrm{L} ; \mathrm{R}=$ resistant $\mathrm{EC}_{50}>0.12 \mathrm{mg} / \mathrm{L} .{ }^{\mathrm{c}}$ Mean percent relative germination (\%RG) on medium amended with technical grade trifloxystrobin at $2 \mathrm{mg} / \mathrm{L}$ relative to that on non-fungicide amended medium. ${ }^{\mathrm{d}}$ Frequency of the resistant allele (A143) of populations determined by qPCR.

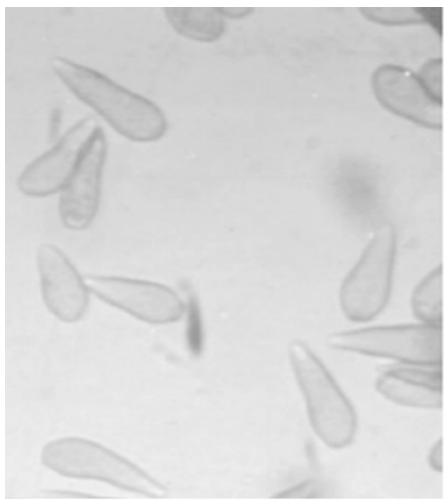

(a)

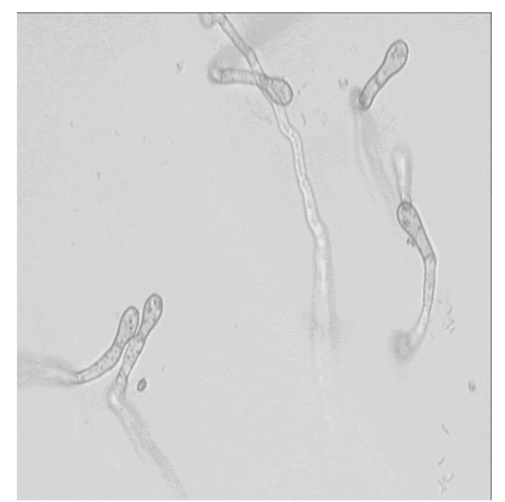

(b)

Figure 2. Effect of trifloxystrobin on spore germination of $V$. inaequalis. (a) Sensitive population (N.62) and (b) resistant population (N.87) on water agar amended with 2 $\mathrm{mg} / \mathrm{L}$ of trifloxystrobin.

results concur with the reports of others [17]. Populations obtained from good control orchards had RG ranging from 0 to $14.6 \%$ (Table 2, Column B). They often showed slightly low sensitivity with respect to wild types but they are also considered sensitive.

Thirty-two populations sampled mainly in orchards that were reported to have poor control (PC) by strobilurins demonstrated resistance with a wide range of RG values from 15.4 to $97.3 \%$ (Table 2, Column B and Figure 2). As 
regards the further four populations, three from treated orchards without use of strobilurins in the sampling year (No 201, 600, BA3) and one from an orchard with unknown field management (No 612), they showed low sensitivity with mean RG values ranged from $14.6 \%$ to $71.8 \%$.

\subsection{Standard Curves and Primer Set up for qPCR}

The qPCR analysis showed a specific amplicon using the primer-set for both $\mathrm{R}$ and $\mathrm{S}$ alleles. The melting curve analyses for all amplicons showed a single peak, and no non-specific products or primer-dimer formation were detected (data not shown). The standard curves obtained using mixed strains (50\% S + 50\% R) in 10-fold serial dilution showed good efficiency (E) with these primer sets (FwS5418/5548URev), (FwR5418/5548URev) for qPCR ranging from $\mathrm{E}=100.1 \%$ to $\mathrm{E}=101.9 \%$, with a linear correlation coefficient of 0.999 (Figure 3 ). The high efficiency for each gene allowed the assumption that the genes are amplified with the same efficiency, and an average slope of -3.329 was used in the equation.

The specificity primer tests were carried out utilizing FW S5418/R5548U and FW R5418/5548U primer sets (Figure 1).

Successful allele discrimination was achieved and an excellent reliability related to the $\Delta \mathrm{C}_{\mathrm{q}}$ calculation method was observed.

\subsection{Relation between R-Allele Frequencies and Relative Germination (RG)}

In vitro resistance response to trifloxystrobin was expressed as RG. The populations were classified as sensitive with RG $<14.6 \%$ and they were found to contain mutated alleles from $0.015 \%$ to $21.32 \%$. Referring to WT and UNT populations, when the relative germination is $0 \%$, the mutated alleles generally ranged from $0 \%$ to $2.28 \%$. Sometimes there was no clear relationship between the frequency of A143 allele and RG. For instance, when populations (No 426, 158,
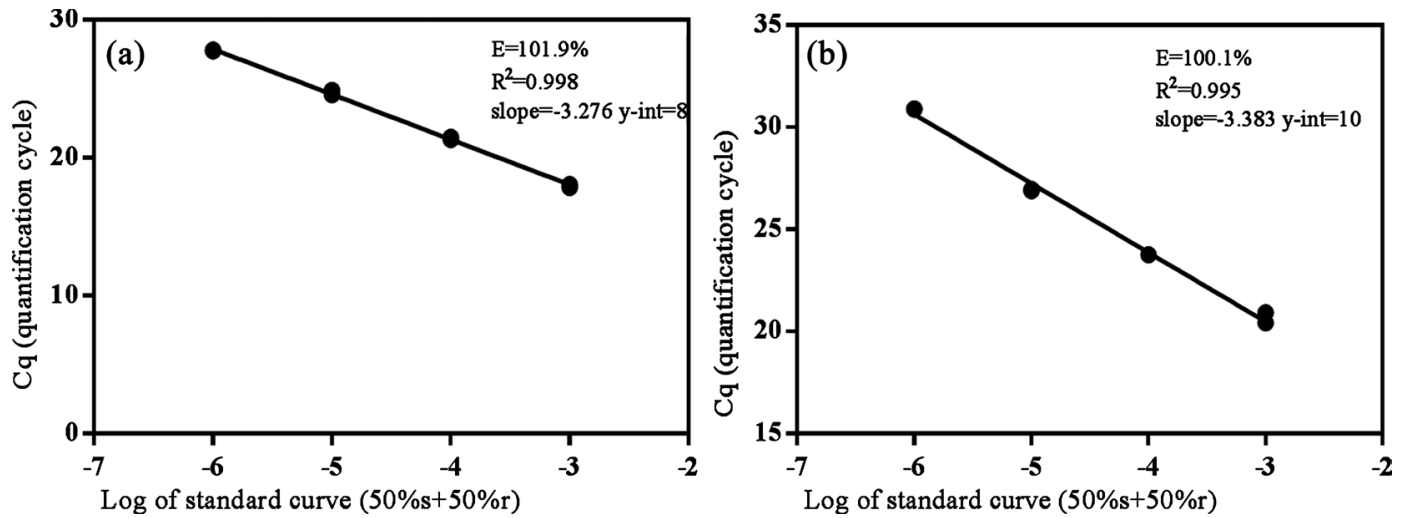

Figure 3. Standard curve with both S5418 sensitive primer (a) and R5418 resistant primer (b) qPCR Standard curve: Ten-fold dilutions obtained using mixed strains $(50 \% \mathrm{~S}+50 \% \mathrm{R})$ of plasmidial DNA ranging from $20 \mathrm{ng} \times 10^{-3}$ to $20 \mathrm{ng} \times 10^{-6}$ were used, as indicated on the $\mathrm{x}$-axis, whereas the corresponding cycle threshold $(\mathrm{Cq})$ values are presented on the y-axis. Each dot represents the result of triplicate amplifications of each dilution. The correlation coefficient and slope values of the regression curve were calculated. 
228,226 ) had RG ranging from $0 \%$ to $2.4 \%$, the resistant allele frequency was $17.55 \%$ to $21.32 \%$, the same as a population sampled from the orchard where strobilurin gave good disease control and had high R-allele frequency (84.5\%) (No 427).

Starting from No 319, the populations obtained from orchards that were reported to have poor control (practical resistance) were defined as resistant by conidial germination test and showed progressively high levels of RG (from 15.4\% to $97.3 \%$ ) (Table 2, Column B). They exhibited the G143A substitution with a higher R-allele frequency, compared to the wild type populations, ranging from $23.01 \%$ to $99.54 \%$. Only two cases (Nos. 201 and 161) were outside this range and, the R-allele frequency was much lower $(0.015 \%$ and $5.97 \%)$ (Table 2 , Column C).

\section{Discussion}

In this study, an allele-specific qPCR method with a newly designed primer set was successfully developed to quantitatively determine the frequency of QoI-resistant A143 allele in populations of $V$. inaequalis in order to substitute the biological assays. In order to be able to suggest only this methodology for the monitoring of $V$. inaequalis we determined how the frequency of mutated alleles relates to the strobilurin resistance, and fundamental was the relationship between in vitro sensitivity tests and molecular assay results.

The results of conidial germination assays (RG) demonstrated differences in sensitivity to strobilurins among populations collected from orchards with different fungicide use and different disease control by these fungicides. In sensitive populations, RG detected within wild-type and well-controlled populations were lower than $<14.6 \%$. Additionally, in most cases, the A143 allele frequencies were lower than $2.28 \%$ while RG was $0 \%$. By contrast, frequency distributions of the mutated allele of resistant populations were variable. In fact, in some cases, a high in vitro sensitivity with low RG corresponded to a moderately high detection of R-allele frequency in four wild type populations (Nos. 426, 158, 226, 228) and one well controlled (No 427) population. Detection of R-alleles in wild type populations may be explained by the natural flow of spores from strobilurin-treated orchards to wild-types, with the spores travelling up to 15 kilometres. It is important to notice that the resistant one can reproduce and spread over the sensitive populations, and this can lead to an increase of resistant isolates [35] [41] [42]. This indicates, as suggested by Fraaije et al., [28] that isolates with A143 alleles might play an important role in long-distance dispersal of QoI-resistant genotypes. Moreover, the Fungicide Resistance Action Committee (FRAC) has also shown that it is possible to detect G143A substitutions in fungal populations never exposed to QoI fungicides. An explanation for this phenomenon is, that mutations occur naturally in fungal populations, usually at low frequencies [43]. Mutations can also be found, at low, but variable, frequencies, in situations where the use of QoI based products is providing perfectly accept- 
able disease control. Furthermore, it should be clarified why mutated alleles with $17.55 \%$ to $21.32 \%$ frequencies, especially in wild types, is not reflected in in vitro sensitivity tests. This case can be explained by the detection of mutated allele in DNA from both non-viable and viable fungal material using qPCR.

The thirty-two populations collected from orchards where strobilurins were applied and poor control was noticed showed lower sensitivity to trifloxystrobin and they presented RG from $15.4 \%$ to $97.3 \%$, therefore they were classified as resistant. It was observed that populations defined as resistant (PC, NOS,) in in vitro tests almost always had high mutated allele frequency (from $23.01 \%$ to 99.54\%). However, two populations, No 161(PC) and No 201(NOS) associated with low sensitivity responses in vitro had a low relative abundance of the A143 allele $(5.97 \%$ and $0.015 \%)$. This difference may be explained by the presence of other mechanisms causing reduced sensitivities. Indeed, the mutation could not always explain the QoI-resistant phenotype, this it $\mathrm{t}$ may be due to the alternative respiration pathway but this phenomenon has been considered of little importance under field conditions [44]. Moreover, the other effective mechanisms responsible for QoI resistance are still to be characterized and could be clarified with studies on biochemical and genetic aspects [20] [44]. Many basic aspects of QoI resistance (e.g. genetic stability, segregation) are still not well understood [45].

In this study, quantitative assessments using qPCR followed a similar pattern to that obtained using in vitro conidial germination tests in very sensitive and very resistant populations. In fact, in most cases, it was noted that when RG was $<10 \%$, mutated allele frequency was $<10 \%$ and when RG was $>70 \%$, very high mutated allele $(>80 \%)$ was detected. Similar results were observed in a large number of monoconidial isolates (data not shown). However, some variability between the two tests was observed in heterogeneous populations (presence in the samples of leaf lesions colonised by either mutant or wild type isolates and/or presence of heteroplasmic fungal strains containing mitochondria with or without the G143A substitutions in the leaf samples.

The results demonstrated that a high relative abundance of the A143 allele was associated with high resistance to QoIs. Furthermore, in the current study, the A143 allele was higher than $23 \%$ in the orchards, where QoIs failed to control apple scab. Similarly, Villiani et al., [36] reported that in the US, commercial orchards with practical resistance to QoI fungicides had a relative abundance of the A143 allele > 22\%.

The qPCR method is able to determine the development of fungicide resistance in apple scab populations and it is a fundamental step in being able to predict possible trends in fungicide resistance on a large scale. More often, it is necessary to detect the presence of the pathogen early and quickly, and to determine the frequencies of resistant and sensitive isolates in one or more regions. The most commonly used test for determining QoI sensitivity of $V$. inaequalis is a biological test, often conducted at several concentrations and which is very com- 
plex, this conventional methods to detect resistance are time-consuming and labor-intensive. Additionally, culturing of $V$. inaequalis is a difficult step because the growth is very slow on culture medium and cross contamination of other fungi occurs very often. The method developed here was designed as a substitution to the traditional method in vitro sensitivity test.

\section{Conclusion}

In conclusion, with this work, after processing a large amount of data with different scab management, we can conclude that qPCR analysis could be performed alone without the biological test especially with a high number of samples in order to efficiently and quickly determine the presence of mutated alleles to identify the practical resistance risk in the orchards, with the certainty that the results are consistent and close to the field situation.

\section{Acknowledgements}

We thank Dr. Riccardo Fiaccadori (University of Bologna) for providing some important strains of $V$. inaequalis and sharing his experiences in bioassays.

This study was partially funded by the Emilia Romagna region within the Rural Development Plan 2014-2020 Op. 16.1.01-GO PEI-Agri-FA 4B, Pr. 5004934 and coordinated by CRPV, the authors are thankful for this financial support.

\section{Conflicts of Interest}

The authors declare no conflicts of interest regarding the publication of this paper.

\section{References}

[1] Fiaccadori, R., Gielink, A. and Dekker, J. (1987) Sensitivity to Inhibitors of Sterol Biosyntesis in Isolates of Venturia inaequalis from Italian and Dutch Orchards. Netherland Journal of Plant Pathology, 93, 285-287. https://doi.org/10.1007/BF01998204

[2] Ammermann, E., Lorenz, G., Schelberger, K., Wenderoth, B., Sauter, H. and Rentzea, C. (1992) BAS 490F-A Broad-Spectrum Fungicide with a New Mode of Action. Proceedings of the 1992 Brighton Crop Protection Conference-Pests and Disease, 1, 403-410.

[3] Sauter, H. and Ammermann, E. (1996) Strobilurins from Natural Products to a New Class of Fungicides. In: Copping, L.G., Ed., Crop Protection Agents from Nature. Natural Products and Analogues, The Royal Society of Chemistry, Cambridge, 50-81.

[4] Brunelli, A., Gianati, P. and Flori, P. (2002) Verifiche sperimentali sull'attività di recenti fungicidi contro la ticchiolatura del melo. Atti Giornate Fitopatologiche, 2 , 215-226.

[5] Gisi, U., Chin, K.M., Knapova, G., Farber, R.K., Mohr, U., Parisi, S., Sierotski, H. and Steinfeld, U. (2000) Recent Developments in Elucidating Modes of Resistance to Phenylamide, DMI, and Strobilurin Fungicides. Crop Protection, 19, 863-872. 
https://doi.org/10.1016/S0261-2194(00)00114-9

[6] Heaney, S.P., Hall, A.A, Davis, S.A. and Olaya, G. (2000) Resistance to Fungicides in the QoI-STAR Cross Resistance Group: Current Perspectives. Proceedings of the 2000 Brighton Crop Protection Conference-Pests and Disease, Brighton, 18-21 November 2000, 755-762.

[7] Bartlett, D.W., Clough, J.M., Godwin, J.R., Hall, A.A., Hamer, M. and Parr-Dobrzanski, B. (2002) The Strobilurin Fungicides. Pest Management Science, 58, 649-662. https://doi.org/10.1002/ps.520

[8] Gisi, U., Sierotzki, H., Cook, A. and McCaffery, A. (2002) Mechanisms Influencing the Evolution of Resistance to QoI Inhibitor Fungicides. Pest Management Science, 58, 859-867. https://doi.org/10.1002/ps.565

[9] Sierotzki, H., Frey, R., Wullschleger, J., Palermo, S., Karlin, S., Godwin, J. and Gisi, U. (2006) Cytochrome $b$ Gene Sequence and Structure of Pyrenophora teres and $P$. tritici-repentis and Implications for QoI Resistance. Pest Management Science, 63, 225-233. https://doi.org/10.1002/ps.1330

[10] Zheng, D., Olaya, G. and Köller, W. (2000) Characterization of Laboratory Mutants of Venturia inaequalis Resistant to the Strobilurin-Related Fungicide Kresoxim-Methyl. Current Genetics, 38, 148-155. https://doi.org/10.1007/s002940000147

[11] Sierotzki, H., Wullschleger, J. and Gisi, U. (2000) Point Mutation in Cytochrome $b$ Gene Conferring Resistance to Strobilurin Fungicides in Erysiphe graminis f. sp. tritici Field Isolates. Pesticide Biochemistry and Physiology, 68, 107-112. https://doi.org/10.1006/pest.2000.2506

[12] Ishii, H., Fraaije, B.A., Sugiyama, T., Noguchi, K., Nishimura, K., Takeda, T., Amano, T. and Hollomon, D.W. (2001) Occurrence and Molecular Characterization of Strobilurin Resistance in Cucumber Powdery Mildew and Downy Mildew. Phytopathology, 91, 1166-1171. https://doi.org/10.1094/PHYTO.2001.91.12.1166

[13] Pasche, J.S., Wharam, C.M. and Gudmestad, N.C. (2002) Shift in Sensitivity of Alternaria solani (Potato Early Blight) to Strobilurin Fungicides. Proceedings of the 2000 Brighton Crop Protection Conference-Pests and Disease, Brighton, 18-21 November 2000, 841-846.

[14] Lu, Y.L., Sutton, T.B. and Ypema, H. (2003) Sensitivity of Alternaria mali from North Carolina Apple Orchards to Pyraclostrobin and Boscalid. Phytopathology, 93, s54.

[15] Ma, Z., Felts, D. and Michailides, T.J. (2003) Resistance to Azoxystrobin in Alternaria Isolates from Pistachio in California. Pesticide Biochemistry and Physiology, 77, 66-74. https://doi.org/10.1016/j.pestbp.2003.08.002

[16] Olaya, G., Zheng, D. and Köller, W. (1998) Differential Responses of Germinating Venturia inaequalis Conidia to Kresoxim-Methyl. Pesticide Science, 54, 230-236. https://doi.org/10.1002/(SICI)1096-9063(1998110)54:3\%3C230::AID-PS815\%3E3.0. CO;2-O

[17] Küng Färber, R.B., Chin, M.K. and Leadbitter, N. (2002) Sensitivity of Venturia inaequalis to Trifloxystrobin. Pest Management Science, 58, 261-267. https://doi.org/10.1002/ps.443

[18] Kuck, K.H. and Mehl, A. (2003) Trifloxstrobin: Resistance Risk and Resistance Management. Pflanzenschutz Nachrichten Bayer, 56, 313-325.

[19] Wood, P.M. and Hollomon, D.W. (2003) A Critical Evaluation of the Role of Alternative Oxidase in the Performance of Strobilurin and Related Fungicides Acting at the $\mathrm{Q}_{\mathrm{o}}$ Site of Complex III. Pest Management Science, 59, 499-511. 
https://doi.org/10.1002/ps.655

[20] Steinfeld, U., Sierotzki, H., Parisi, S., Poirey, S. and Gisi, U. (2001) Sensitivity of Mitochondrial Respiration to Different Inhibitors in Venturia inaequalis. Pest Management Science, 57, 787-796. https://doi.org/10.1002/ps.356

[21] Jabs, T., Cronshaw, K. and Freund, A. (2001) New Strobilurin Resistance Mechanism in Apple Scab (Venturia inaequalis). Phytomedizin, 31, 15-16.

[22] Fiaccadori, R., Cicognani, E., Abbatecola, M., Collina, M. and Brunelli, A. (2005) Sensitivity of Venturia inaequalis to Strobilurin Fungicides in Italy. Agricultural and Applied Biological Sciences, 70, 73-78.

[23] Sallato, B.V., Lattore, B.A. and Aylwin, G. (2006) First Report of Practical Resistance to QoI Fungicides in Venturia inaequalis (Apple Scab) in Chile. Plant Disease, 90, 375. https://doi.org/10.1094/PD-90-0375A

[24] Fontaine, S., Remuson, F., Fraissinet-Tachet, L., Micoud, A., Marmeisse, R. and Melayah, D. (2008) Monitoring of Venturia inaequalis Harbouring the QoI Resistance G143A Mutation in French Orchards as Revealed by PCR Assays. Pest Management Science, 65, 74-81. https://doi.org/10.1002/ps.1649

[25] Fiaccadori, R., Cicognani, E., Collina, M. and Brunelli, A. (2011) Sensitivity to Strobilurin Fungicides of Italian Venturia inaequalis Populations with Different Origin and Scab Control. Pest Management Science, 67, 535-540.

https://doi.org/10.1002/ps.2090

[26] Fraaije, B.A., Butters, J.A., Coelho, J.M., Jones, D.R. and Hollomon, D.W. (2002) Following the Dynamics of Strobilurin Resistance in Blumeria graminis f.sp. tritici Using Quantitative Allele-Specific Real-Time PCR Measurements with the Fluorescent Dye SYBR Green. Journal of Plant Pathology, 51, 45-54. https://doi.org/10.1046/j.0032-0862.2001.00650.x

[27] Luo, Y., Ma, Z., Reyes, H.C., Morgan, D.P. and Michailides, T.J. (2007) Using Real-Time PCR to Survey Frequency of Azoxystrobin-Resistant Allele G143A in Alternaria Populations from Almond and Pistachio Orchards in California. Pesticide Biochemistry and Physiology, 88, 328-336. https://doi.org/10.1016/j.pestbp.2007.01.009

[28] Fraaije, B.A., Cools, H.J., Fountaine, J., Lovell, D.J., Motteram, J., West, J.S. and Lucas, J.A. (2005) Role of Ascospores in Further Spread of QoI-Resistant Cytochrome b Alleles (G143A) in Field Populations of Mycospaerella graminicola. Phytopathology, 95, 933-941. https://doi.org/10.1094/PHYTO-95-0933

[29] Sirven, C. and Beffa, R. (2003) Resistance to Fenamidone: Monitoring by Real Time PCR on Plasmopara viticola. Pflanzenschutz Nachrichten Bayer, 56, 523-532.

[30] Collina, M., Landi, L., Guerrini, P., Branzanti, M.B. and Brunelli, A. (2005) QoI Resistance of Plasmopara viticola in Italy: Biological and Quantitative Real-Time PCR Approaches. In: Dehne, H.W., Gisi, U., Kuck, K.H., Russell, P.E. and Lyr, H., Eds., Modern Fungicides and Antifungal Compounds IV, British Crop Production Council, Alton, 81-88.

[31] Kianianmomeni, A., Schwarz, G., Felsenstein, F.G. and Wenzel G. (2007) Validation of a Real-Time PCR for the Quantitative Estimation of a G143A Mutation in the cytochrome $b c_{1}$ Gene of Pyrenophora teres. Pest Management Science, 63, 219-224. https://doi.org/10.1002/ps.1290

[32] Dufour, M.C., Fontaine, S., Montarry, J. and Corio-Costet, M.F. (2011) Assessment of Fungicide Resistance and Pathogen Diversity in Erysiphe necator Using Quantitative Real-Time PCR Assays. Pest Management Science, 67, 60-69.

https://doi.org/10.1002/ps.2032 
[33] Wille, P., Sierotzki, H., Stanger, C., Cleere, S., Burbidge, J., Hall, A., Wind-ass, J. and Gisi, U. (2002) Qualitative and Quantitative Identification of SNPs in Plant Pathogens. In: Dehne, H.W., Gisi, U., Kuck, K.H., Russell, PE. and Lyr, H., Eds., Modern Fungicides and Antifungal Compounds III, British Crop Production Council, Alton, 131-139.

[34] Turan, C., Nanni, I.M., Brunelli, A. and Collina M. (2015) New Rapid DNA Extraction Method with Chelex from Venturia inaequalis Spores. Journal of Microbiological Methods, 115, 139-143.

https://doi.org/10.1016/j.mimet.2015.06.005

[35] Michalecka, M., Malinowski, T., Broniarek-Niemiec, A. and Bielenin, A. (2011) Real-Time PCR Assay with SNP-Specific Primers for the Detection of a G143A Mutation Level in Venturia inaequalis Field Populations. Journal of Phytopathology, 159, 569-578. https://doi.org/10.1111/j.1439-0434.2011.01805.x

[36] Villiani, S.M. and Cox, K.D. (2014) Heteroplasmy of the Cytochrome $b$ Gene in Venturia inaequalis and Its Involvement in Quantitative and Practical Resistance to Trifloxystrobin. Phytopathology, 104, 945-953. https://doi.org/10.1094/PHYTO-06-13-0158-R

[37] Turan, C., Nanni, I.M., Tosun, N. and Collina, M. (2015) First Report of QoI Resistance in Venturia inaequalis Causing Apple Scab in Apple Orchards in Turkey. Plant Disease, 100, 1016. https://doi.org/10.1094/PDIS-10-15-1139-PDN

[38] Jaklova, P., Kloutvorova, J. and Cmejla, R. (2000) A Real-Time PCR Quantitative Analysis of the Venturia inaequalis cytb Gene G143A Mutation and Its Prevalence in the Czech Republic. European Journal of Horticulture Science, 85, 169-175. https://doi.org/10.17660/eJHS.2020/85.3.4

[39] Köller, W., Parker, D.M., Turechek, W.W. and Avile-Adam, C. (2004) A Two-Phase Resistance Response of Venturia inaequalis Populations to the QoL Fungicides Kresoxim-Methyl and Trifloxystrobin. Plant Disease, 88, 537-544. https://doi.org/10.1094/PDIS.2004.88.5.537

[40] Bustin, S., Benes, V., Garson, J.A., Hellemans, J., Huggett, J., Kubista, M., Mueller, R., Nolan, T., Pfaffl, M.W., Shipley, G.L., Vandesompele, J. and Wittwer C. (2009) The MIQE Guidelines: Minimum Information for Publication of Quantitative Real-Time PCR Experiments. Clinical Chemistry, 55, 611-622. https://doi.org/10.1373/clinchem.2008.112797

[41] Aylor, D.E. and Sutton, T.B. (1992) Release of Venturia inaequalis Ascospores during Unsteady Rain: Relationship to Spore Transport and Deposition. Phytopathology, 82, 532-540. https://doi.org/10.1094/Phyto-82-532

[42] McHardy, W.E. (1996) Apple Scab: Biology, Epidemiology and Management. The American Phytopathological Society, St Paul.

[43] Rusell, P.E. (2002) Sensitivity Baselines in Fungicide Resistance Research and Management. In: FRAC Monograph, No. 3, Crop Life International, Brussels, 328-330.

[44] Fernandez-Ortuno, D., Tores, J.A., Vicente, A. and Perez-Garcia, A. (2008) Mechanisms of Resistance to QoI Fungicides in Phytopathogenic Fungi. International Microbiology, 11, 1-9.

[45] Gisi, U. and Sierotzki, H. (2008) Molecular and Genetic Aspects of Fungicide Resistance in Plant Pathogens. In: Dehne, H.W., Gisi, U., Kuck, K.H., Russell, P.E. and Lyr, H., Eds., Modern Fungicides and Antifungal Compounds V, 53-61. 